\title{
LEONA ENTRE LAS LEONAS, TRADICIÓN ESCRITURAL FEMENINA: AMOR, LIBERTAD Y PALABRAS ${ }^{1}$
}

\author{
Lilia Granillo Vázquez ${ }^{2}$ y Liliana Fort Chávez ${ }^{3}$
}

\begin{abstract}
Leona entre las leonas, tradición escritural femenina: amor, libertad y palabras
Resumen: Se destaca la contribución de Leona Vicario, heroína de la Independencia mexicana, creadora de opinión pública y gestora del discurso de las mujeres ante el pensamiento sistémico. Las acciones y manifestaciones expresas de Leona Vicario sugieren la tradición femenina de libertad, de salvaguarda del territorio con intuición ecologista, más allá de proyectos masculinos. Lecturas de otras leonas impulsan el estudio de esta pionera y su atrevida ocupación de la plaza pública con palabras fuertes y conocedoras.

Palabras clave: Leona Vicario, Independencia Mexicana, Santa Inquisición, pioneras, prensa decimonónica.
\end{abstract}

\section{Leona among Lionesses, Female Scriptural Tradition: Love, Freedom and Words}

Abstract: Leona Vicario, heroine of Mexican independence, reveals herself as a creative builder of public opinion and women's discourse on systemic thinking. Actions and statements of Vicario suggest the female tradition for freedom, for safeguarding the territory with environmental intuition beyond male projects. Readings about other lionesses and the study of this women pioneer reinforces his audacious occupation of public space and public opinion with strong words and knowledge.

Key words: Leona Vicario, Mexican Independence, Spanish Inquisition, pioneers, NineteenthCentury Press.

\section{Leonas al servicio de la patria}

Dios sabe si hay o no Dulcinea en el mundo o si es fantástica o no es fantástica; y éstas no son de las cosas cuya averiguación se ha de llevar hasta el cabo. Ni yo engendré ni parí a mi señora, puesto que la contemplo como conviene que sea una dama (Cervantes 2006: 800).

${ }^{1}$ Fecha de recepción: 24/09/2015.

Fecha de aceptación: 30/10/2015. ${ }^{2}$ Profesora Titular, Departamento de Humanidades, y Responsable del CA UAM 105, Estudios culturales: género, lenguajes y sustentabilidad, Universidad Autónoma Metropolitana-Azcapotzalco, Ciudad de México, República Mexicana; \liliagranillo@gmail.com, clgv@correo.azc.uam.mx.

${ }^{3}$ Profesora titular, Departamento de Derecho, Área Filosofía del Derecho, Universidad Autónoma Metropolitana-Azcapotzalco, Ciudad de México, República Mexicana; $\$ lilifort@correo.azc.uam.mx. 
Elena Poniatowska, escritora mexicana nacida en París, descendiente de reyes y príncipes polacos, recibió en noviembre de 2013 el Premio Cervantes. Elena, Elenita, lo recibió como máximo reconocimiento -dicho suyo- por su obra literaria, testimonial, comprometida con luchas sociales y con las de las mujeres. En las primeras entrevistas concedidas a la prensa, luego del galardón, habló de las escritoras y su escritura femenina. Sus palabras sirvieron de aliento para esta investigación. "Las mujeres están siempre en la parte de atrás, son siempre las leonas. El león era Carlos Fuentes, Mario Vargas Llosa. Las mujeres siempre acaban de dar a luz, son feas, las leonas son feas, las olvidan, no les hacen caso. Es muy bueno que se empiece a reconocer la literatura de las mujeres" (Montaño 2003). Hablar de felinas feroces explica la condición de las mujeres, de escritoras y abogadasque se afanan por salir de la opresión patrarcal, por ocupar su lugar en la plaza pública:

Ana Rosa Domenella antes había establecido la metáfora leonina para el campo mexicano de las letras femeninas. La colección de investigaciones de una docena de críticas literarias reunidas en el taller Diana Morán, de Ciudad de México, ostenta nombre emblemático y de acción afirmativa. La obra se llama Territorio de Leonas: Cartografía de narradoras mexicanas en los noventa. El estudio de mujeres que escriben en el siglo XX traza la ocupación paulatina de la escritura femenina sobre la plaza pública. Revela el proceso de transformación, liberación y avance de la voz de las autoras y sus protagonistas.

En las jóvenes escritoras las miradas ya no son las modeladas por el patriarcado, ni la "mirada bizca" que proponía la crítica alemana Sigfrid Weigel, sino otra, desinhibida, sin culpas ni remordimientos y francamente sexuada. El "Territorio de leonas", desplegado para los muchos o pocos lectores de narrativa mexicana contemporánea, propone la aventura de transitar por esos espacios de los márgenes que los cartógrafos del siglo XV advertían como inexplorados y, en consecuencia, peligrosos para los viajeros. La leyenda de "Aquí hay leones" para referirse al lenguaje de la mujer, "a su cuerpo verbal" que fue utilizado por primera vez por la escritora argentina Luisa Valenzuela en un artículo titulado "The other face of the fallus" y retomado después por la crítica literaria feminista (Domenella 2001: 41). 
Celia del Palacio, leona ella misma -tercera mención- escribió una novela histórica sobre Leona Vicario, para II Centenario de la Independencia Mexicana. La escritura de Leona convalida la tradición leonina en el ambiente literario nacional. Celia, historiadora de la prensa, comunicóloga, profesora de la Universidad Veracruzana, investigadora nacional, mujer de letras, narradora, ni es fea, ni se queda atrás, ni es olvidada. La biografía novelada de esta rica criolla (hija de españoles, nacida en Nueva España), famosa por abandonar la comodidad del palacio y andar por los montes huyendo del ejercito realista, brinda conocimiento de las acciones de mujeres valerosas, rebeldes, inteligentes y estrategas que Celia abona con otra en investigación Adictas a la insurgencia. Armada de documentos históricos y evidencias de archivos de la Inquisición, Celia ubica la vida amorosa y familiar de esta gran mujer y la explica con el amor al territorio; la inquietud espiritual; la defensa de hijos e hijas, biológicos y naturales de la tierra. Celia demuestra que Leona, esposa del abogado insurgente, Padre de la Patria, Andrés Quintana Roo, acometió la lucha por la libertad, incluso a veces con mayor enjundia y compromiso que Don Andrés. Y sin decirlo, nos asegura que muchas otras mexicanas con palabras y argumentos, buscaban liberarse.

Los libros de la historia nacional recuerdan a Leona Vicario por haber dado a luz en una cueva, pues seguía a su esposo, Andrés Qunitana Roo, abogado, jurista insurgente, en sus aventuras contra los realistas. En contraste, Celia divulga el razonamiento audaz, las palabras fuertes con que Leona se defiende de la Inquisición y de sus contemporáneos. En 1831, en el periódico Registro Oficial, el notable Lucas Alaman clasificaba las acciones de mujeres independentistas, las Leonas, como resultado de pasiones románticas motivadas por amor a los insurgentes. He aquí la enjundiosa autodefensa de Leona ante la invectiva:

Mi objeto en querer desmentir la impostura de que mi patriotismo tuvo por origen el amor, no es otro que el muy justo de que mi memoria no pase a mis nietos con la fea nota de haber sido yo una atronada que abandoné mi casa por seguir a un amante. Me parece inútil detenerme a probar lo contrario, pues además de que en mi vindicación hay suficientes pruebas, todo México supo que mi fuga fue de una prisión y que ésta no la originó el amor, sino el haberme apresado a un correo que mandaba yo a los antiguos patriotas. En la correspondencia interceptada, no 
apareció ninguna carta amatoria, y el mismo empeño que tuvo el gobierno español para que yo descubriera a los individuos que escribían con nombres fingidos, prueba bastantemente que mi prisión se originó por un servicio que presté a mi patria. Si usted cree que el amor fue el móvil de mis acciones, ¿qué conexión pudo haber tenido éste con la firmeza que manifesté, ocultando, como debía, los nombres de los individuos que escribían por mi conducto, siendo así que ninguno de ellos era mi amante? (Del Palacio Montiel, Leona 2010 : 342)

¿Interesada en algo más que vestidos y afeites para enamorar varones? ¿Una mujer que en 1810 presta servicio a la patria, lucha por las mujeres, por la justicia social, como la Poniatowska? De Leona Vicario solían mofarse llamándola "El Quijote con faldas". Como se verá, este memorial vale para trazar el linaje femenino de las dulcineas, la intuición ecologista de las mujeres que amonestan, como la aldeana del Toboso, a quienes maltratan a la Madre Tierra y a quienes maleducan a los seres humanos haciéndolos creer que son los dueños de la Creación y que por ello pueden destruir la naturaleza. En 2015, los líderes y un puñado de lideresas de 195 países discutieron por vigésima primera vez, en París, en la Cumbre de la ONU sobre Cambio Climático, la crisis ambiental que afecta al planeta, a nuestra Tierra, la Casa de la Humanidad. Se antoja ahora recordar la labor y las palabras de una mexicana ejemplar, una precursora de nosotras y del ecofeminismo. Universalmente desde el poder se discute y se reglamenta disminuir las venenosas emisiones de $\mathrm{CO}_{2}$; regulación que nadie cumple, o no sería esta la Cumbre número 21. Cabe pues conocer y divulgar la escritura de quien se ocupaba ya de cuidar el planeta y regular la vida en estas tierras hace más de 200 años.

\section{Una mujer ilustre e ilustrada y el árbol del conocimiento}

María de la Soledad Leona Camila nació en la capital de Nueva España el 23 de junio de 1787. Hija de don Gaspar Martín Vicario, quien fuera honrado con el cargo de Regidor vitalicio de la Ciudad de México. Peninsular, español de abolengo, amasó una fortuna y reafirmó nombre y posición en Nueva España al casarse en segundas nupcias con doña Camila Fernández de San Salvador y Montiel. Ella nacida en Toluca, y 
descendiente de la nobleza acolhua (Del Palacio Montiel 2010b: 23), de los pueblos originarios, diríamos ahora. Doña Camila era una de cinco hermanos. Dos de ellos, Gaspar y Fernando, fueron abogados y llegaron a ocupar honrosos cargos en la Real Audiencia y en la Real y Pontificia Universidad. Eruditos, juristas, fueron autores de varias obras novohispanas. La madre de Leona recibió igual educación que sus hermanos, aunque a ella no se le conoce cargo público alguno. Otro notable y erudito fue padrino de Leona, don Agustín Pomposo. Por ello, Leona recibió una educación esmerada. Pero a diferencia de lo que se esperaba de las mujeres de su tiempo, ella decidió cultivar una vida pública. Asistía a tertulias y encuentros culturales, y así conoció a otras hijas de notables con pensamiento independentista. A doña Josefa Ortiz de Domínguez, morisca, y doña Mariana del Toro y Lazarín, intrépida. Recibió instrucción superior a la de otras, limitadas a los cautiverios de esposas, monjas, beatas, madres abnegadas y consumistas -diriamos hoy-. Sus padres, Gaspar y Camila vieron en Leona un talento especial, supieron que la educación desarrolla las virtudes y corrige los vicios de hijos e hijas.

Ávida lectora, Leona estudió La idea del universo, del jesuita Lorenzo Hervas y Panduro. Ahí aprendió de la vida de los seres humanos, la cosmografía, la historia de la Tierra. De la Historia natural general y particular, del conde Georges Louis Leclerc Buffon, obtuvo enseñanzas sobre el origen, desarrollo, variaciones y degeneraciones del planeta. Leyó tambien El nuevo Robinson de Campe, una historia moral traducida del alemán por Tomás de Iriarte. Por supuesto, el Don Quijote de la Mancha, y el Teatro crítico universal de Benito Feijóo. Se enteró entonces del amor que sería "el príncipe de las pasiones" y móvil de todas las acciones humanas; cuyo vasto imperio no conoce límites, por lo que revuelve y trastoca imperios. Y de Feijóo aprendió también a combatir las supersticiones que tanto entorpecen y retardan la marcha evolutiva de la humanidad. Con todo, Las aventuras de Telémaco, el viaje del hijo de Ulises en busca de su padre, acompañado de Mentor, el tutor fue lectura favorita, pinturas y frescos adornaban su casona. Fenelón escribió, hacia 1699, esta novela pedagógica, casi manual para un futuro rey. Leona la tradujo del francés al español. Nótese el interés educativo, la intuición humanista y la intención ilustrada para contener la avidez humana: 
[Telémaco] dejábase llevar del apetito propio, sin advertencia alguna. Habíalo, su madre Penélope, a pesar de Mentor, criado con una altivez, y un orgullo, que deslucían todo lo que en él se encontraba de apreciable. Estimábase como de otra naturaleza que el resto de los hombres, y no le parecía que los dioses habían puesto a los otros sobre la tierra sino para darle gusto, para servirle, para prevenir cualquier deseo suyo, y para referir a él todas sus acciones como a una deidad [...]. Era un vivo exemplo de la desgracia de aquellos que nacen en sublime fortuna [...]. Pero, en tanto que Telémaco estaba con Mentor, no crecían estos defectos y, más bien, se iban disminuyendo de día en día. ${ }^{4}$

Francois Salignac de la Mothe-Fénelon, arzobispo de Cambrai, fue preceptor del heredero al trono francés, el sobrino del rey Luis XIV. Escritor irónico, autor de varios libros sobre la educación de los jóvenes, fue un favorito de Leona, pues describía el proceso civilizatorio y de socialización, de re-ligación, del organismo inteligente que nace con pasiones de dominio y, sin freno socializante, se convierte en tirano. Leona leyó ahí que "el pueblo elegido de Dios" no lo era por raza, ni por la fuerza de algún ídolo o alguna otra característica terrena, sino por la capacidad de exhortar a naciones, pueblos y personas a organizarse en comunidades mediante la comunicación, la voz pública.

Leona se convenció que sólo mediante la palabra compartida y pública podría esperarse que todos y todas en el futuro convivieran en paz. Obtuvo el impulso de fundar el futuro de las generaciones del mundo siguiendo la religión natural, la unión de la vida comunitaria. Luchó contra las supersticiones de la religión institucional que manipulaba opiniones de los súbditos - estado inicial de Telémaco-; en cambio se convenció de procurar que cada uno, cada una aprendiese el arte de gobernar cultivando la tierra, manteniendo la paz, reprimiendo la maldad, amando a la niñez, dando pasos ilustrados. Aprendió a compartir la fidelidad entre los seres humanos y el amor a los dioses no sólo por miedo, sino por temor a olvidar lo espiritual, a alejarse de lo trascendente que no es más que el futuro de las generaciones humanas. En palabras de otro biógrafo, su desarrollo intelectual se inclinaba a lograr la cohesión en el pueblo, la constitución social,

\footnotetext{
4 Medalla de François de Salignac de La Mothe-Fénelon. http://mismuseos.net/comunidad/metamuseo/recurso/medalla-de-franois-de-salignac-de-lamothefenelon/e2e84317-d2e9-454a-8b83-d60ea8232783
} 
haciendo renunciar a cada uno al "vicio engendrado de las necesidades fútiles" (García 1910: 43).

Este pensamiento ilustrado de principios del siglo XIX, coincide con las nociones de co-evolución biológica y de la teoría del discurso universal de intelectuales del tercer milenio, como los latinoamericanos Varela y Maturana. Se reconoce en ello el movimiento evolutivo en su organización autopoiética. Cabe recordar que un organismo es autopoiético cuando se diferencia del medio circundante mediante "un conjunto de procesos interrelacionados para mantener constantemente en vida al organismo" (Maturana y Varela 2003: 28). El germen de la vida, la célula es un organismo autopoiético. A partir de las provocaciones o estímulos del medio externo reestructura lo interno, para acoplarse con quienes recursivamente se mueven igual, y así se mantienen constantemente en vida. Así surgen los seres multicelulares. Son organizaciones autopoiéticas que mediante la interrelación con el medio se reestructuran y acoplan, dando lugar a las sociedades instintivas, igualmente organizadas autopoiéticamente. Perecen las especies que no se reestructuran ni se acoplan a la totalidad de procesos interrelacionados.

\section{Derecho y religión natural}

En la naturaleza, ante una especie que desaparece, surgen otras mejor adaptadas al todo eco-sistémico. En la dinámica de la vida, la especie que tiene más interrelaciones con el medio avanza; es la que enfrenta más problemas y logra resolverlos. Así se desarrolla la inteligencia: capacidad de registrar aquello que se repite y de evolucionar o crear tecnología, innovar. Con todo, la inteligencia puede convertirse en atributo ajeno a la sociabilidad: con el sueño de poder que a veces proviene del conocimiento, el ser humano tiende a individualizarse, a cerrarse en grupos instintivos. Se detiene la marcha evolutiva: se dispersa el acoplamiento y se propicia la autodestrucción. ¿Qué lugar ocupan la justicia, la regulación jurídica, el cuerpo normativo en esta dinámica vital? Reducción simplista es pensar que el derecho - uno de los ejes de análisis- es un mero orden coactivo 
de la conducta. Reduccionismo que menosprecia la fuerza vital del conocimiento comunitario, compartido; simplificación que detiene la evolución de la humanidad. En cambio, Leona Vicario - protagonista de este ensayo- concibió el derecho en su manera compleja: en la constitución del tejido social a partir del debate público de historias y de formación de identidad humana. La inteligencia de Leona tiende hacia la educación de las pasiones y el cultivo de las emociones sociales. Educación y cultivo que fueron criminalizadas por las fuerzas represivas de reyes y virreyes, o bien, por las fuerzas ideológicas de la iglesia institucional.

La misión de Leona fue la nueva conformación de identidades hacia la emergencia de un mundo ecológico terreno y de una economía de los hogares nativos. La religión institucional no garantizaba dicha evolución ni progreso histórico: su noción de derecho es simplificada y autoritaria; corrompe el proceso de constitución social e identidad humana. Leona marcó la diferencia: su religión fue natural. Immanuel Kant planteó que el motivo de obediencia a la norma es su universalidad formal; pero el motivo subjetivo de obediencia es la representación que "todo ser racional hace de su existencia como un fin en sí mismo valioso y no meramente como un medio o herramienta” (Kant 1967: 60). El valor de la persona es su dignidad. Éste es el límite al derecho que marca la constitución social. Este valor de la persona se refleja en su honor, reconocimiento merecido por aquellos que sirven a la patria.

Morín, humanista actual, dice: "La percepción de la ecología es espiritual o religiosa: se ubica en el orden orgánico del mundo" (Morin 2000: 37). Justamente en esta percepción nuestra heroína se ordena y organiza: a partir de sus intuiciones. El concepto de ecología no alude a una nomenclatura simplista, como aquellos miran por sus terrenos. Aquí se llama a la ecología compleja, profunda, la que reconoce el valor intrínseco de todos los seres vivos y ve a los y las humanas como una de tantas hebras de la trama de la vida. La ecología se define como ciencia que estudia las relaciones de los seres vivos entre sí y con su entorno (Kraus y Pérez Tamayo 2007: 66). El término deriva de la voz griega oikós, casa u hogar. He aquí la más elevada de las ciencias de la vida, pues tiene que ver con la economía de la Gran Casa, que es la naturaleza. Se ocupa de establecer su estructura y función en el espacio-tiempo, y en conocer las interacciones de animales y 
plantas y materiales entre sí; y las relaciones de unos con otras. En la ecología profunda de la insurgente mexicana está la intención de integrarse a la interrelacionalidad de los procesos de la vida orgánica, a la reintegración de las tierras a los nativos y el respeto de la persona humana.

Cabe hacer hincapié en la diferencia entre concepciones religiosas. Cada una impulsa diferentes resultados y expresa ideas divergentes sobre el derecho y el orden social. La religión institucional del Virreinato fue autoritaria, delimitada a un espacio geográfico. La religión de Leona Vicario fue organización de la civilización planetaria, con una visión del futuro de las generaciones, a partir de educar las opiniones y creencias ciudadanas. Vista así, la organización planetaria no es un problema metafísico, sino civilizatorio.

\section{Vida y amores de Leona}

Leona amaba a Dios sobre todas las cosas, pero sabía que Dios era una imagen de identidad para discutir el proyecto humano. Sabía también que las vírgenes son la proyección de la maternidad. No tomó preferencias por la Virgen de los Remedios ni por la Virgen de Guadalupe, como hicieron realistas o insurgentes. De la primera, española, traída por Hernán Cortés, se decía que no hablaba con los indígenas; de la segunda, que se apareció en América para consolar a los nativos, sus hijos más débiles. Leona había oído que la madre de Dios "bajo todas sus advocaciones abre a todos el seno de su misericordia" (García 1910: 32) a semejanza de una madre terrena que a todos provee y perdona a todos.

Prometida en matrimonio con Octaviano Obregón, ilustrado de familia rica, Leona abrazó la causa de la independencia y apoyó las quejas de la familia Obregón contra los abusos de virreyes y oficiales. El padre de Octaviano tuvo que desterrarse, el hijo lo siguió a España, y el matrimonio se aplazó. La persecución contra los independentistas había comenzado. Ya el obispo de Puebla hablaba de "ex comunión" para quienes apoyaran a 
los criollos rebeldes (Aguirre 2010: 26). El verdadero amor de Leona llegaría con Andrés Quintana Roo, joven yucateco que estudio leyes. Nacido en 1787, de padres con ideas avanzadas y cierto desahogo pecuniario, para graduarse de abogado, además de hacer "profesión de fe católica y juró obedecer al rey, a los virreyes, a los rectores y defendería la doctrina de nuestra señora concebida sin pecado original" (García 1910: 56), debía practicar jurisprudencia dos años. Andrés eligió el despacho de Agustín Pomposo, padrino y guardián de Leona, jurista que fuera dos veces rector de la universidad. Ahí coincidió con Leona, quien lo aventajaba en su amor a la tierra mexicana y la libertad.

Otro biógrafo pone en boca de nuestra heroína estas palabras dichas a su tío Agustín: "Me llamo Leona y quiero vivir libre como una fiera" (Aguirre 2010: 20). La libertad es el bien supremo de la humanidad, una libertad ajena a la fantasía de dar rienda suelta a los instintos. Supo ella que la libertad personal termina cuando comienza la libertad del otro, y que no hay libertad sin la posibilidad de saber y medir las consecuencias de cada acto y decisión tomada, de manera que cada individuo se responsabilice de sus decisiones y acciones. La libertad alcanza concreción en una república, la sede pública donde se debate y argumenta la vida común. Los criollos, hijos de peninsulares nacidos en Nueva España, y los y las mestizas como Leona defendían esta libertad, bajo el ideal de soberanía popular. Se apoyaban en lecturas de Rousseau y otros ilustrados. En 1765, la Inquisición había prohibido por edicto el Discurso sobre la desigualdad entre los hombres, por sus cláusulas que "inducían al deísmo y al ateísmo". En 1799, el Santo Tribunal recogió ejemplares del Contrato social: "merece especial anatema, porque anima a los vasallos de su magestad a sublevarse" (Villoro 2005). A pesar de las censuras, los y las insurgentes pensaban en cómo conservar la libertad y formar un orden de renuncias e identidades humanas. Rousseau hablaba de la entrega total de los derechos del hombre a la sociedad, bajo la concepción de que el hombre es una persona y la sociedad un cuerpo viviente. El problema estaba en la representación: la delegación del poder político por parte de los ciudadanos a un grupo. Delegar la soberanía o capacidad de decidir a una élite es dañoso, pues la soberanía pertenece al pueblo, su titular legítimo. Lo ideal sería la interrelación, una comunidad sin separación de gobernante y gobernado. Así, intuía la formación de un organismo autopoiético. 
En los salones de Leona se deliberaba que el ser humano es más que voluntad egoísta y ciega; sobre todo es también razón, conciencia y reflexión. Por ello, ve más allá de su perímetro subjetivo. Percibe valores universales, participa en instancias que lo trascienden y a la vez permanece en donde está, pues es su entorno lo que ha de cambiar. Esta capacidad permite escuchar una voluntad que no es la suya propia, sino la voz de la comunidad o voluntad general, que expresa los intereses socialmente modelados. Diego Fusaro lo explica hoy de esta manera: "La voluntad general es la expresión de nosotros mismos, obedeciéndola, la humanidad se obedece a sí misma, es decir, la parte más racional y moral de cada uno. Por eso, una tal obediencia pone en acto la única libertad digna de ese nombre" (Fusaro, s.d.).

En el edicto de excomunión contra Miguel Hidalgo y Costilla, el sacerdote que encabezara el movimiento de libertad de los criollos, el 16 de septiembre de 1810 , se lee que: "pintó en su estandarte la imagen de nuestra augusta patrona, Nuestra Señora de Guadalupe, y le puso la inscripción siguiente: Viva la Religión. Viva nuestra Madre Santísima de Guadalupe. Viva Fernando VII. Viva la América y muera el mal gobierno" (Sierra et al. 1985: LXIII)._Esta imagen llegó a manifestar la voluntad general de indios, españoles y castas, hombres y mujeres, ricos y labradores, peones e indígenas, que armados con piedras, palos, hondas y machetes iban a la guerra de independencia detrás del estandarte siguiendo ideas inspiradas en la religión natural. El poder hacia el pueblo, aun dentro de la monarquía, donde el rey sólo sería coordinador del debate de historias y no un emperador:

Sin diferenciar estamentos o clases, Hidalgo puso por soberano al pueblo bajo, sentando con ello nuevos criterios políticos del criollo ilustrado. Al legislar para el pueblo, Hidalgo hizo todo lo posible por cumplir con su voluntad: suprimió los tributos que pesaban sobre él; abolió la distinción de "castas", que tanta humillación había provocado en la gente del campo; decretó la confiscación de los bienes de los europeos y dictó la primera medida agraria, consistente en la restitución a las comunidades indígenas de las tierras que les pertenecían. Además quedó abolida la esclavitud. (González 1973: 83) 
Un par de años después, los realistas fusilaron a Hidalgo. Hubo quien continuara la causa. Se levantó José María Morelos y Pavón. Andrés atendió el llamado de unirse al cura rural y hubo que suspender los esponsales con Leona. Se fue. A mediados de 1812 comenzó la labor de la prensa independentista, que Leona encabezaría tan bien luego. Desde el Semanario Patriótico Americano se dinfundía el ideario insurgente: "Confirmar a la Nueva España en su heroica resolución de conquistar su libertad, y demostrar a todo mundo la justicia, la necesidad y la conveniencia de la insurrección". Andrés visualizaba una "nación llena de majestad y grandeza, que camina por el sendero de la gloria a la inmortalidad del vencimiento" (García 1910: 60-61).

También armadas con la prensa, las autoridades eclesiásticas combatieron a los insurgentes con injurias. Los hicieron aparecer como bandidos de la peor especie, y ni siquiera exentaban de la pena de muerte a las mujeres. Las y los tildaban de herejes sacrílegos, furias del infierno condenados al fuego eterno. Por miedo a estas supersticiones, muchos mexicanos se apartaron de la guerra. Pero no Leona. Ella fue una de las primeras en contactar jefes insurgentes e impulsar partidarios de la independencia cohibidos por los tremendos edictos eclesiásticos. Convirtió su casa en centro de comunicación para difundir logros y organización. Escribía para alentar a los insurrectos con frases de simpatía; evitó muchos golpes a la insurrección que pudieron haberla sofocado. Mantenía correspondencia con esposas y familias de insurgentes, daba noticias y las tranquilizaba. También le escribía a Andrés sobre la independencia, causa que siempre los unió.

El tránsito de la sociedad instintiva e inteligente hacia la sociedad humana del planeta Tierra no es algo que llegará necesariamente, sino que es un evento contingente: depende de que alguien ponga las condiciones para debatir historias y se vean con transparencia los costos sociales que pueden producir nuestras decisiones: "Leona fue el conducto por el cual se comunicaban los patriotas de México" (Aguirre 2010: 85.) En su casa, plaza pública, se gestaba la opinión comunitaria; se debatían historias pasadas y posibles historias futuras. Circulaban periódicos, se formaba la opinión en las nuevas identidades. ¡Sapere aude!, si la ilustración, como decía Kant, es la liberación del hombre de su culpable incapacidad, entonces Leona era una ilustrada: ¡tenía el valor de servirse 
de su propia razón! (Kant 1970: 25). Involucraba a sus amigas, a familiares y ayudas domésticas y campesinas de sus haciendas:

\begin{abstract}
A mi casa llegan todo el tiempo mensajeros de nuestras haciendas de Mañí y Peñol. ¿Quién se va a extrañar? Además, se me ha ocurrido un sistema para disimular nuestras comunicaciones: nos pondremos nombres falsos. Tú -dijo apuntando a su amiga Margarita-, serás "Bárbara Guadalupe" y los paquetes que yo reciba te los mandaré a ti. Usted -se dirigió al prometido de Margarita-, va a ser "Telémaco"; y usted, don Juan Raz, por el parentesco, será mi "tío"; don Benito Guerra será "el compadre" de todos nosotros; don Antonio será "Lavoisier"; don Andrés Quintana Roo será "Mayo" y don Carlos María será "Nemoroso". (Del Palacio Montiel 2010: 45)
\end{abstract}

Para ella, la ciudadanía debía participar y pensar orgánicamente: desde la realidad de un Estado cuya constitución social es protegida por las normas y principios de lo que sería la constitución política. Mujer talentosa, planeó la "seducción de los armeros", para que fueran a Tlalpujahua a fabricar fusiles. Habló con sus mujeres y se convirtió en el sostén económico de sus familias, mientras fueran convencidas de la causa. Gastó gran parte de su fortuna en ayudar a la insurrección; logró atraer hacia la causa a muchos letrados criollos. Muchos propietarios, terratenientes e industriales, junto con la iglesia, siguieron apoyando a los realistas. Poco duró la clandestinidad y el subterfugio de los códigos de personajes de novelas, como Robinson, Telémaco, Lavoisier. Aprehendieron a Mariano Salazar, su correo, con un saco de esquelas para ella, todas en clave. Anastasio Bustamante, de la Junta Real, recibió el caso y lo remitió al virrey. Leona, advertida por quienes la amaban, aunque no la secundaran, al salir de misa decidió que era el momento para unirse con los insurgentes. Sin dinero y a pie, acompañada de mujeres fieles, disfrazada, llegó a Huixquilucan; no alcanzó a llegar ni a Tlalpujahua, ni a Oaxaca, donde la esperaba Andrés. Cuando su padrino Agustín se enteró, mandó cartas a Leona, que le entregó el notable don Antonio del Río: se negó a volver y no aceptó el indulto que el padrino le entregaba: eso sería una traición a su causa. No juraría fidelidad a quienes esclavizaban a su patria. Regresó a su casa engañada, le dijeron que podía salir del 
escondite sin indulto. Ignoraba que al rechazar la gracia, sería irremisiblemente procesada. A los dos días, don Agustín la llevó al Colegio de Belén, como reclusa forzada.

\section{El proceso de Leona}

Si bien evitó que la llevaran a la cárcel. "La reclusión de Leona en el Colegio produjo mayor sensación que su fuga, y ocupó la atención de la prensa española" (García 1910: 94). En su expediente sólo constaba una carta de Andrés, que un detenido, e indultado después, llevó a Leona. La carta nada decía de amores, hablaba de "la mala" causa de la independencia de la Nueva España. La Junta Real remitió la documentación al juez, quien ordenó ir a la casa de Leona por los relojes y la traducción de Las aventuras de Telémaco. Pero los oficiales sólo encontraron páginas sueltas.

Desde el primer día del alzamiento de Hidalgo, don Agustín Pomposo se declaró monárquico. En su código, la soberanía o potestas de legibus soluta se deposita en el rey, cabeza del gobierno, y éste es responsable únicamente delante de Dios. En ese código estaba la iglesia institucional, implacable en sus procedimientos cuando se trataba de defender sus reinos terrenales. Excomulgaba a cualquiera que intentase despojarla de sus propiedades. Privaba a las personas, con esa pena grave de los santos sacramentos y, sobre todo, de la comunicación con los demás. El poder civil también reprimía el delito de traición o difidencia con la muerte y la infamia para los hijos. Pero Leona tenía otro sentido del honor y la dignidad. Recluida, nunca dio un solo dato ni un solo nombre de los insurgentes por los cuales le preguntaban. Aunque la voluntad general no era igual de resistente: "sucedía que los insurgentes, al ser procesados, casi nunca podían salvarse negando que se hubieran alzado contra el monarca porque se les obligaba a jurar, vínculo importante, para su convicción; pues quien juraba falsamente cometía doble pecado: profanaba en nombre de Dios y engañaba a los hombres" (García 1910: 100).

Lograban convencer de que Dios castigaba en ésta y en la otra vida; se manipulaba la fe y la opinión de muchos insurgentes. Más que por temor a las prisiones, confesaban 
por estas creencias. No podían esperar imparcialidad, los jueces eran nombrados por el rey. Los insurgentes perdían su entereza, se hablaba de excesos de los insurrectos. Para escarnio y horror, se exponían en las plazas públicas los cuerpos, cabezas y órganos para amedrentar a los simpatizantes e infamar a los alzados.

En el interrogatorio, Leona no perdió su carácter. Respondió con aplomo y dijo que se había ausentado porque una mujer le había avisado de que la detendrían. Reconoció sus cartas y documentos, pero nunca dijo el significado de las claves. Nunca delató a nadie. Sólo habló de su primo Manuel y del licenciado Quintana, pues sabía que estaban con los insurgentes y ningún perjuicio les causaría.

Para cuando el juez la declaró formalmente presa en el colegio, el 20 de marzo de 1812, ya le habían sido incautados parte de sus bienes. Nunca se retractó. Más que martir, Leona fue heroica: no se ocupó de salvarse ella, pues salvando a los demás se consideraba salvada. Era sincera, dócil, simpática, bonita, educada y generosa, dentro de la escuela todas la querían. Cuando por la cercanía insurgente ya se preparaba su traslado a prisión, fue rescatada con la ayuda de amigas - una que otra monja-que había hecho en la escuela.

La escapatoria despertó el interés de todos: Leona se convirtió en leyenda. Muchos comenzaron a admirarla, otros concluyeron que era herética. Fernández de Lizardi la alabó discretamente. La tuvieron escondida, pues todas las garitas fueron avisadas de la orden de arresto. Cuando la vigilancia disminuyó, salió para el sur, disfrazada de negra, con unos arrieros. En los burros llevaba la tinta y letras de molde para la imprenta. Su primo Manuel y Andrés se apuraron para ayudarla. Desde Chilpancingo, Morelos le escribió agradeciéndole tanto los donativos como su labor comunicativa.

En 1813, año en que finalmente se casaron Leona y Andrés, Morelos se desprendió del poder a favor del Congreso de Chilpancingo. El matrimonio se ocupó de la prensa de los insurgentes. Tal y como lo anota otra biógrafa, "Para el amor, como para la libertad, la palabra es el mejor alimento" (Balestra 2010: 64). Sin importar la autoría, las ideas comunes iban firmadas por Morelos. Símbolo de la nueva identidad y aun así, generoso y modesto, Morelos delegó el poder al Congreso con la idea de que la nación tuviese un 
cuerpo de hombres sabios que la rigiesen en leyes acertadas, y dieran a la soberanía el aire de majestad que le correspondía.

La notoriedad pública tiene dos funciones, explica Habermas: la crítica y la manipuladora. Ambas son claramente distinguibles y actúan socialmente contrapuestas. Cada una conlleva una expectativa diferente sobre la conducta del público: la crítica busca la opinión del público que razona, pues es libre; la manipuladora busca la opinión pública aislada, que es tomada en cuenta selectivamente por el poder. En el sentido de la primera: "La opinión pública es la única base reconocida de la legitimación del dominio político. Por ella, el Estado moderno presupone como principio de su propia verdad a la soberanía popular, y ésta, a su vez, tiene que estar encarnada por la opinión pública" (Habermas 2006: 262).

Sin la ficción de la opinión pública como origen de toda autoridad, de las decisiones obligatorias para todos y todas (tomadas por las autoridades que nos representan), falta a la democracia moderna la sustancia de su propia verdad. Leona tenía la intuición de que la religión debe ser el vínculo de unión de todos los organismos inteligentes en una voluntad general; y la noción de la soberanía como el sustento a todos sus hijos y en la organización de los hablantes. En cambio para los realistas, la soberanía aún recaía en manos de una sola persona, el rey, y en un sistema que lo respaldaba manipulando opiniones y creencias, induciendo miedo al castigo de dioses, amos y gobernantes.

La pareja Quintana-Vicario se distinguió en el Congreso. Andrés asumió la presidencia y firmó el manifiesto del 6 de noviembre de 1813. En resumen, los congresistas planteaban que los mexicanos indistintamente habían estado condenados a los rigores de la tiranía, excluidos de los empleos y de la menor intervención en los asuntos públicos. Las leyes y el monopolio de la metrópoli mantenían esterilizados los campos, cerrados los puertos, desterradas las artes y cegadas las fuentes de riqueza pública. Por eso, la Nueva España se había organizado para la emancipación y ésta comenzaría en la comunicación pública. En el acta del Congreso se rechazaba la monarquía y se establecía una república, disposiciones que todavía se conservan en la Constitución. 
Ya en los Sentimientos de la Nación, Morelos establecía que "la América es libre e independiente de toda otra nación" y que "la religión católica será la única sin tolerancia de otra". Siguiendo nuestra línea interpretativa, mencionemos que la libertad, como la posibilidad de conocer los riesgos que produce cada decisión, implica una concepción compleja del derecho. En ese sentido, los intelectuales de la insurgencia entendían que sin la formación de una ciudadanía razonante no habría nación soberana. El pueblo, cada hablante, necesita identificarse como organismo inteligente y digno para tomar el poder, sin importar que el gobernante sea un rey, pues sólo será el organizador y no impondrá decisiones. Contrariamente, los realistas seguían profesando una concepción de derecho simplificada: un orden coactivo de conducta y la identidad social fabricada mediante supersticiones, encabezado por gobernantes que toman decisiones sin organizar al cuerpo social y produciendo descontento social.

La guerra se recrudeció y Morelos, ya sin Hidalgo, decidió tomar la ciudad principal de Valladolid. Los realistas, comandadas por Ciriaco del Llano y Agustín de Iturbide se prepararon y hubo una batalla feroz. Los insurgentes no tenían alimentos, ni armas: fueron encarnizadamente perseguidos. Aprendieron a Morelos y lo fusilaron en 1814. Entonces Leona y Andrés huyeron al campo.

Mientras, en la capital, Leona había sido convocada mediante numerosos edictos y pregones, pues se decía que se había burlado de la autoridad judicial al declarar lo que quiso y como quiso. En 1815 el virrey dispuso del caudal que el Consulado de Veracruz le reconocía. Leona siguió peregrinando con el Congreso ya disuelto y con su marido. A petición de su familia, aprovechando que el jefe realista, por mando del virrey, estaba ofreciendo indultos a diestra y siniestra, se les otorgó la gracia del indulto, con la condición de separarse de la causa insurgente. "Leona rechazó este ofrecimiento reiterada y categóricamente, [...] ella se había afiliado a la causa precisamente para liberar a la nación de ladrones y asesinos" (Aguirre 2010: 139). Andrés, pensando en tender una emboscada a los realistas, fingió aceptarlo, para tener tiempo de prepararla. Para 1816, se opinaba que el movimiento insurgente estaba en agonía y muchos se habían acogido al indulto. Leona protestaba por la deserción y seguía pensando en cómo conformar la soberanía popular y una voluntad común. Vicente Guerrero se había hecho indestructible, 
por lo que Leona confiaba en que los criollos que habían probado la libertad ya no regresarían a ser parte de España. Huyendo de cueva en cueva y escondiéndose en la sierra, la pareja tuvo a su hija Genoveva en 1817. Sobrevivieron pobremente. Una mañana los sorprendieron y Andrés tuvo que huir, no sin antes escribir una petición de indulto para ellas. "Orgullosa ella no quiso pedir el indulto, por lo que Andrés su marido se entregó para que la liberaran" (Alaniz 2009: 38). Fue indultado. Pero obligado a salir con su familia del país, no se exilió pues Calleja, el virrey, no restituyó los recursos incautados a Leona.

La defección de Iturbide del bando realista y la abnegación de Guerrero, que declinó el mando independentista en el antiguo jefe realista, dieron el poder a Iturbide, quien se autoproclamó emperador de México. Andrés fue nombrado subsecretario de Estado y del Despacho de Relaciones Interiores y Exteriores, a pesar de que siete años antes, Iturbide había perseguido encarnizadamente a la pareja. Leona volvió a gozar del brillo y alta posición social; aunque en lo íntimo nunca estuvieron de acuerdo con Iturbide.

Organizaron el trabajo. Él regresó a ser escritor y abogado; ella a estar a cargo de sus hijas: así escribiría para el periódico. Ya era conocida como "la primera mujer periodista en México" (Pascual 2010: 112). Escribió en El Ilustrador Americano de Morelos durante la lucha, y en El Federalista durante la época de independencia. Leona y Andrés miraron que no había otro camino que defender las libertades políticas y religiosas, aunque el emperador no estuviera de acuerdo. Iturbide notó que sus ideas estaban diametralmente opuestas a las adoptadas en las bases constitucionales del 24 febrero de 1822, concretamente que "la religión católica, apostólica, romana sería la única religión de Estado y la monarquía moderada su forma de gobierno" (García 1919: 136). Como los realistas tenían una concepción supersticiosa de la religión, Leona y Andrés pensaron que se justificaba plenamente la apertura a otros credos. Iturbide destituyó a Andrés debido a estas declaraciones, y éste huyó a Toluca para evitar la aprehensión. Antes, dirigió una carta a Iturbide diciendo que "él no había encubierto opiniones, sólo no había tenido oportunidad de decirlas; y que no era un crimen el haber instruido al pueblo en un asunto de tanta trascendencia" (García 1919: 140). 
A su vez, el "emperador" fue desterrado: el soberano Congreso se ocupó de honrar la memoria de los insurgentes muertos y de recompensar a los sobrevivientes. Se ordenó la devolución del capital que el Consulado había confiscado a Leona. Ella no se vio codiciosa y aceptó que le pagaran con dos fincas y dos casas aunque no cubrían el valor de su fortuna legítima. Las insurrecciones se siguieron, con traiciones y cambios de gobiernos y personas, como en toda guerra civil.

\section{La voz de Leona: Ni frenillo ni pepita en la lengua}

Se conservan pocos documentos con ideas de Leona, pues no firmaba en el Ilustrador de América. Algunos textos conciernen a su proceso y a intervenciones en la vida pública, generalmente defendiendo la nueva República y mostrando a los lectorcómo debería funcionar un Estado de Derecho: el poder es comunicativo y la soberanía la ejercita el pueblo. Eficazmente, Andrés publicaba en El Federalista Mexicano su abierta oposición a Bustamante. Cuando éste mandó cuatro soldados para recoger la imprenta y los periódicos a la casa de los Quintana Roo, se encontraron con Leona. Dos de ellos, estuvieron platicando con ella y los otros dos se apostaron en la puerta para impedir que ésta fuera cerrada. Leona, que al inicio no se dio cuenta de esto, temió que su marido fuera víctima de algún atentado y ese mismo día, al anochecer, fue a pedir la protección de la autoridad pública al presidente Bustamante. Le relató el allanamiento de morada del que había sido víctima y expresó su temor, puntualizando que "si su marido se excedía con sus escritos, debía ser reprimido con otros escritos y no con medios violentos" (Carta de Leona, en García 1919: 179).

Madre, esposa, hacendada, la sostenía el poder de sus convicciones: el debate público era necesario por ser el inicio del derecho y la instancia de formar la identidad humana al interno de una nación. Pero Bustamante y su séquito concebían al derecho simplificado en el poder coactivo. Así que mandó llamar a Codallos, jefe del ejército, para que explicara las cosas. Éste dijo que había sido atacado por Quintana Roo en El 
Federalista, por lo que se había hecho indispensable contestar a palos a los escritores, y que él no sabía dar otra respuesta puesto que no sabía escribir. Asombrada por tal concepción y por el descaro de un empleado público delante del primer magistrado de una república libre, Leona contestó que la conducta impune de cuatro hombres armados que asaltaban las casas para vengarse de un ciudadano, sólo probaba que "debía considerarse disuelta la sociedad y restituida a cada uno la obligación de defenderse por sí mismo" (Carta de Leona, en García 1919: 152).

Extrañada estaba, de que hubieran aparecido tales desfacedores de entuertos, que en lugar de sacar las espadas en pro de los desvalidos y doncellas menesterosas, ${ }^{5}$ no trataban sino de vindicar a garrotazos el honor de unos individuos, que bien podían pedir satisfacción personalmente. Pero la ignorancia de Codallos y la falta de honor de Bustamante quedaron impasibles ante la ironía. Leona dijo a Bustamante que "no siendo sultán de Constantinopla, sino jefe de una República libre, no debía permitir que en su presencia se hiciera aquella burla de las leyes, por un funcionario como Codallos" (García 1910: 180). Indignada, puso fin a la audiencia, no sin antes manifestar que había ido allí para saber si podía contar con la protección de la autoridad, o si debía defenderse ella sola, como en el estado de naturaleza. Bustamante dijo que dentro de su casa podía contar con la protección, pero no fuera. Y, desde entonces en México, bajo el amparo del concepto simplificado de derecho como "orden coactivo de la conducta', se han venido legitimando las autodefensas, a veces ante la ignorancia del pueblo, que sigue siendo excluido del debate de historias.

Mucho se habló de esta entrevista. El Sol, periódico gobiernista, trató de ridiculizar a Leona. Publicó que la apoderada y esposa de Quintana Roo, había solicitado escandalosamente al presidente el castigo de unos oficiales, a quienes ningún cargo se podía hacer, "a menos que se castiguen las intenciones". Ni tarda ni perezosa, al otro día Leona dirigió un comunicado a los editores de ese diario, en el cual negaba que hubiese pedido con escándalo que fuesen castigados los oficiales Merino y Antepara; que no lo hubiera solicitado ni en el caso de que los referidos señores hubieran cometido un crimen,

\footnotetext{
${ }^{5}$ Leona y Bustamante parafrasearon los términos de Don Quijote de la Mancha.
} 
pues su ideas y sentimientos no estaban para pedir venganza de los agravios que le hacían. Tampoco era cierto, afirmaba, que su marido la hubiese nombrado su apoderada porque "no teniendo ni frenillo, ni pepita en la lengua, que le impidiese defenderse, lo hará mejor que yo cuando le parezca oportuno, y a mí no me gusta defender a quien está en posibilidad de poder hacerlo por sí mismo" (Carta de Leona, en García 1919: 140). Pero El Sol no lo publicó, pues estaba muy ocupado burlándose de ella, presentándola como “Quijote con enaguas". Leona escribió una nota para El Federalista Mexicano. Mostró que el presidente y Codallos veían fraguar crímenes sin dictar ninguna medida oportuna. Tal fue la orden de fusilar a Guerrero, por tratar de recuperar el poder que Bustamante le había arrebatado.

Como el Registro Oficial, órgano del Supremo Gobierno, dijo que había atendido a Leona y recomendado a Codallos que tomara medidas oportunas, Leona aclaró: "nadie me ha conocido como deslenguada y atrevida, no podrá discernir un solo lineamiento del original en el injurioso retrato que de mí hace el editor del Registro Oficial, convertido liberista con desdoro de la dignidad del Gobierno, en cuyo nombre habla" (Carta de Leona, en García, 1910: 142). De pronto, el Registro Oficial no se atrevió a replicar a Leona. Pero un mes después, el editor de $\mathrm{El} \mathrm{Sol}$, al contestar un artículo que El Federalista había publicado en contra del Ministro de Relaciones, don Lucas Alamán, aprovechó la oportunidad para decir que Leona: "había recibido casas y haciendas en pago de unos créditos, merced a cierto heroísmo romancesco, que el que sepa algo del influjo de las pasiones, sobre todo en el bello sexo, aunque no haya leído a Madame Stäel, podrá atribuir a otro principio menos patriótico" (Carta de Leona, en García, 1910: 142).

Ya no la llamaron “Quijote con enaguas”, pues podría parecer más un cumplido que una burla. Ahora, profesando un discurso simplista, se la comparaba con una "mujer de partido”, con aquellas que Cervantes pintó yéndose con el primero que les pasa por enfrente, para ayudar a tal hombre y secundar cualquiera causa que él siga. Leona, ofendida porque un compatriota, Lucas Alamán, manchara su reputación y buen nombre de insurgente abnegada y dama honorable. Por esto, replicó con esta nota: 
[...] ya otra persona había querido ver un efecto de amor en sus servicios a la patria y que entonces ella imprimió una vindicación con documentos intachables que destruían por completo semejante impostura, por la cual esa persona tuvo que desdecirse públicamente; que, a pesar que Alamán no ignoraba esto, le remitía un ejemplar de dicha reivindicación en caso de que lo hubiera olvidado. [Advertía Leona que] no aspiraba a granjearse el laurel de heroína, pues sus servicios habían sido"comunes y cortos", sino sencillamente a impedir que su memoria pasara con fea nota a sus nietos. (Carta de Leona, en García, 1910: 143)

En relación a sus bienes, Leona aclaró que las casas que la nación le cedió, las había tomado por su valor íntegro, cuando nadie quería dar por ellas ni las dos terceras partes de su valor, y que no obstante que rendían 1500 pesos, o sea los réditos de un capital de 30 000, ella las había aceptado en pago de 112 000, que era lo que le habían incautado ilegalmente. Alamán no lo publicó, pero El Federalista Mexicano sí. La opinión pública se pronunció a favor de Leona, pues sus detractores no volvieron a combatirla. En cambio, Andrés no dejó de ser perseguido, sin respeto a su fuero de diputado obtenido por representar, precisamente, a la opinión pública.

Vencido Bustamante a fines de 1832, por una revuelta que provocó su tiranía, el matrimonio Quintana Roo gozó de una vida, relativamente, más tranquila. Hubo incidentes, como el robo que en 1838 sufrió su hacienda ubicada en el Estado de México. En esa ocasión les hurtaron ovejas con el valor de 700 pesos. Leona presentó su queja al gobernador, don Valentín Canalizo y, en una primera carta, pidió la devolución de su ganado. Argumentó los 25 años de sacrificios pecuniarios y personales; y que en ese momento, debido a las persecuciones y venganzas injustas de sus "ingratos paisanos", se hallaba bastante atrasada en sus negociaciones e intereses. Debía ser atendida porque pedía justicia; agregó que aun cuando solicitara una gracia como ésta, con objeto de impedir que se repartieran sus ovejas cuatro zaragates que ya le habían saqueado mucho, esperaría que el señor gobernador le guardara las consideraciones a que era acreedora por sus servicios a la patria. Canalizo respondió que ya pediría información a los responsables del atropello. Leona comprendió que el gobernador estaba dando tiempo para que vendieran las ovejas, para imposibilitar que se recuperaran. Justamente resentida, escribió otra carta a Canalizo, haciéndole saber que "nada quería ya de justicia ni de gracia, que 
se conformaba ya con el robo, y, para que le fuese menos sensible, haría cuenta de que existía una guerra extranjera, y que había sido saqueada por los enemigos de la nación" (García 1910: 144). Hubo quien dijera que ella estaba cobrando sus servicios y, por lo tanto, los cuatreros hacían lo mismo con ella. Pero otros comprendieron que ella diferenciaba entre gente con honor que lucha por el ideal de república libre, y la gente sin honor, que aprovecha para robar bienes bajo el amparo de gobernantes que no sólo no distribuyen justicia, sino que permiten delinquir.

Leona fue buena madre y esposa, ciudadana intachable y creyente sincera. Se dedicó a su hogar y a sus negocios, pero siguió siendo una mujer generosa y desprendida de los bienes materiales. Murió en 1842, a los 53 años de edad. Su entonces ya amigo nuevamente, Carlos María Bustamante, la llamó: "el ornamento de su sexo y la gloria de su patria".

Mujeres como Leona hicieron temblar a las autoridades con sus comunicados. Ya lo dijo el oidor Josué Bersueta: un solo escrito que hable en contra de la conquista de la Nueva España, "podría llevar a la religión y al Estado a su total ruina" (García 1910: 34). Pero sólo la educación de los ciudadanos hará recobrar el tránsito hacia la evolución planetaria y el progreso de la historia. Esto no llegará en manera necesaria, sino que es contingente y depende de que surjan personas con la intuición de la organicidad y de su futuro, como Leona, que intuyó la organización autopoiética. Se requiere no una inteligencia mecánica para hacer leyes, sino una inteligencia emotiva para educar opiniones. Ella la tuvo, en su religión laica, en su educación ecológica que privilegió la formación de creencias desde la intuición de la vida futura. En esto consiste la notoriedad de las personas honorables. Hoy día, cimentadas en nuestro linaje de leonas, las mujeres, con nuestros estudios y escrituras, hemos de acometer nuestros horizontes de libertad y nuestra defensa de la Tierra. 


\section{Referencias bibliográficas}

Aguirre, Eugenio. 2010. Leona Vicario: La insurgente. México: Planeta.

Alaniz, Sebastián. 2009. Mujeres por la independencia. México: Lectorum.

Balestra, Bertha. 2010. “Palabra de Leona”, las revoltosas. México: Selector Actualidad Editorial.

Cervantes y Saavedra, Miguel. 2006. El ingenioso hidalgo Don Quijote de la Mancha. Edición del IV Centenario. España: Real Academia Española y Asociación de las Academias de la Lengua Española.

Del Palacio Montiel, Celia. 2010a. Leona. México: Suma de Letras. 2010b. Adictas a la insurgencia. México: Punto de Lectura.

Domenella, Ana Rosa, coord. 2001. Territorio de leonas, cartografía de narradoras en los noventa. México: Casa Juan Pablos y Universidad Autónoma Metropolitana.

Diego Fusaro. La filosofía e i suoi eroi. http:/7www.filosofico.net/Rousseau.htm. [5 feb. 2015].

García, Genaro. 1910. Leona Vicario: heroína insurgente. México: Talleres de Imprenta y Fotograbado del Museo de Antropología, Historia y Etnología.

González, Luis. 1973. "La Revolución de independencia”. Historia mínima de México. México: El Colegio de México.

Habermas, Jürgen. 2006. Historia y crítica de la opinión pública: la transformación estructural de la vida pública. Barcelona: Gustavo Gili.

Kant, Immanuel. 1967. Fundamentación de la Metafísica de las costumbres. México: Espasa Calpe.

1970. “QQué es la ilustración?”. Filosofía de la Historia. México: Fondo de Cultura Económica.

Kraus, Arnoldo y Ruy Pérez Tamayo. 2007. Diccionario incompleto de bioética. México: Taurus.

Maturana, Humberto y Francisco Varela. 2000. El árbol del conocimiento. Argentina: Paidós.

Morin, Edgar. 2000. "La naturaleza de la naturaleza”. El Método, tomo I. “. Madrid: Cátedra. 

Cátedra.

2000. "El conocimiento del conocimiento", El Método, tomo III. Madrid: , Roger Ciurana y Raúl Motta. 2009. Educar en la era planetaria. Barcelona: Gedisa.

Pascual, Carlos. 2010. La insurgenta. México: Grijalbo.

Sierra, Justo, Luis G. Urbina, Pedro Henríquez Ureña y Nicolás Rangel. 1985. Antología del Centenario. México: Universidad Nacional Autónoma de México.

Villoro, Luis. 1977. "La Revolución mexicana", Historia general de México, tomo 2. México: Ediciones del Colegio de México.

2005. "Rousseau en la independencia mexicana". http://www.uam.mx/difusion/casadeltiempo/80_sep_2005/55_61.pdf. [5 feb. 2015]. 